\title{
Impact of Gypsum Particle Size on Soil Physical Properties of a Saline-Sodic Soil from North Sinai, Egypt
}

\author{
M. Abuhashim and M. K. Abdel-Fattah \\ Soil and Water Science Department, Faculty of Agriculture, \\ Zagazig University,Zagazig, Egypt.
}

ATER flow through structured soils can substantially affect
local water balance, contaminant transport, and plant-available
water. Effect of different gypsum radius on hydraulic conductivity
(HC) of saline-sodic soils was assessed. Saline-sodic clay soil from
Gelbana Village, Sahl El-Tina plain, Sinai, was mixed with three
treatment of gypsum $\left(\mathrm{CaSO}_{4} \cdot \mathrm{H}_{2} \mathrm{O}\right)$ different in there particle size:
T1"fine" (<0.5 mm), T2"medium" (0.5-1 mm) and T3"coarse" (1-2
$\mathrm{mm})$, and subjected to continuous leaching increments, and these
treatments were compared by the control. Soil samples were packed in
columns to make a 30 -cm height with a bulk density of $1.36 \mathrm{Mg}$.m-3.
Leaching was conducted by ponding with a constant head of $5 \mathrm{~cm}$
water. Leaching water was of EC 1.50 dSm-1 and SAR of 9.1 . Six
continuous water increments were performed for each column. To
assess and simulate the water flow, to quantify improved management
strategies, and to derive updated irrigation standards, the soil-water
model HYDRUS-1D code was used. Considerable short-lived increase
in HC following addition of gypsum occurred to the soil. It quickly
decreased in subsequent leaching increments. The increase amounted
to 181,126 and $117 \%$ due to the fine-particles, medium-particles and
coarse-particles gypsum, respectively. The increase in HC persisted up
to the $4^{\text {th }}$ leachate; and was particularly marked with the fine-particle
gypsum, and this increases up to $275 \%$ following the $5^{\text {th }}$ leachate
compared with the $1^{\text {st }}$ leachate. In soils receiving medium-particle or
coarse-particle, increased of the HC was less marked, being up to
$56 \%$ following $5^{\text {th }}$ leachate increment. The HYDRUS-1D provided
reliable simulation results of infiltration rate and cumulative
infiltration. Using the model to analyses management options proved
an efficient tool for agro-ecosystem assessment.

Keywords: Water flow, Leaching increment, Hydraulic conductivity, HYDRUS-1D code.

Soil salinity is a latent threat in irrigated agriculture countries of the arid and semi arid regions. Almost 400 million hactares of land is worldwide affected by salinization (Bot et al., 2000). Primary salinization contribute with $80 \%$ of these lands, while the remaining $20 \%$ is "man-made". In addition $1-2 \%$ of the irrigated areas, mainly in arid and semi-arid regions, become unsuitable for agriculture yearly (FAO, 2002). Owing to the arid agro-climatic conditions, crop production in Egypt fully relies on irrigation. By the end of the last century, 
Egypt irrigated land was estimated at 3 million hectares and the area of saltaffected soils was estimated at 0.8 million hectares are located in the northern, eastern part of the Nile Delta and in Sahl El-Tina plain, Sinai Peninsula. In adequate management of irrigation has lead to considerable salinization of the soils in these regions. Secondary soil salinization by capillary rise of shallow groundwater to the rooting zone plays a major role, entailing yield losses and threatening economic growth and development (Willis et al., 1997, Christen et al., 2001, Singh, 2004 and Murtaza et al., 2006).

Gypsum is the common amendment for saline sodic-soils, because of its low cost, availability and ease of handling. Application of gypsum decreases the ratio of sodicity/salinity in percolating solution and enhances the hydraulic gradient of the soil profile (Miyamoto and Enriquez, 1990, Abdurrahman et al., 2004 and Siyal et al., 2002). Gypsum and phosphogypsum decreased swelling of sodic soils and increased their hydraulic conductivity and infiltration rate and sustained soil structure (Bridge and Tunny, 1973, El-Shanawany, 1985, Ramirez et al., 1999 and Leborn et al., 2002).

Infiltration has long been a focus in agriculture and water research because of its role in land-surface and agricultural irrigation (Milla and Kish, 2006 and Abuhashim, 2011). Large numbers of mathematical models have been developed to evaluate the computation of infiltration. Generally, these infiltration models can be classified into physically based models, semi-empirical and empirical models (Mishra et al., 1999). The semi-empirical and empirical models such as Kostiakov and Horton models are often derived from either field and/or laboratory experimental data and are always in the form of simple equations (Lei et al., 1988 and Mishra et al., 2003). However, the semi-empirical and empirical models cannot provide detailed information on infiltration process and their physical impacts. Compared with the semi-empirical and empirical models, the physically- based numerical models can describe the detailed infiltration process and among the physically-based models, is the Richards equation. The Richards equation used the mass conservation law and Darcy's law (Lei et al., 1988). As a physically based model, the Richards equation has been extended into many complex conditions (Brunone et al., 2003, Barontini et al., 2007 and Elmaloglou \& Diamantopoulos, 2008). Nevertheless, the Richards equation is strongly nonlinear and cannot be solved analytically, especially under complex initial and boundary conditions. Numerical methods such as finite difference and finite element methods have been used to solve the Richards equation (Arampatzis et al., 2001). Based on the finite element method, the HYDRUS-1D model was developed to solve the Richards equation and was used to simulate onedimensional water movement invariably saturated media (Šimunek et al., 2005). The soil water model Hydrus-1D was applied to (1) understand and assess the effect of different gypsum radius treatments on the infiltration rate, (2) simulate soil water dynamics under sequential increments of continuous leaching with the

Egypt. J. Soil Sci. 53, No. 1 (2013) 
aim to quantify leaching efficiency and (3) simulate improved management strategies in terms of enhancing the hydraulic conductivity.

\section{Material and Methods}

Sampling and soil preparation

The saline-sodic soil used in this study was collected from the surface $15-\mathrm{cm}$ layer of a field in Gelbana Village, Sahl El-Tina plain, Sinai. The soil had a history of irrigation with El-Salam Canal (EC $1.5 \mathrm{dSm}-1)$. This region has an extreme continental climate with hot dry summer and rather-wet winter (100-mm of precipitation mainly from November to March). Main crops in this region are wheat, barley, beans and maize, fully dependant on Nile irrigation water of ElSalam Canal. Soil samples were physically and chemically characterized by the standard methods of Black et al. (1965) (Table 1). Soil columns were prepared by packing $8.20 \mathrm{~kg}$ of sieved $(<2 \mathrm{~mm})$ and air-dried soil into polyvinyl chloride (PVC) cylinders of 40-cm height and 16- $\mathrm{cm}$ inside diameter and was set in a vertical position. Soil samples were packed in columns to make a $30-\mathrm{cm}$ height with a bulk density of $1.36 \mathrm{Mg} \mathrm{m}^{-3}$. A filter paper disc was put at the bottom of the cylinder with 5-cm layer of acid-washed inert sand (pre-washed with $\mathrm{HCl}$ then by distilled water) to form a sand layer in order to prevent removal of soil particles by the flowing water. The top $5-\mathrm{cm}$ on the soil surface gave sufficient space for adding the leaching process. Before packing, the soils were mixed with three treatment of gypsum $\left(\mathrm{CaSO}_{4} \cdot 2 \mathrm{H}_{2} \mathrm{O}\right)$ different in there diameter: $\mathrm{T} 1$ "fine particles" ( $<0.5 \mathrm{~mm}), \mathrm{T} 2$ "medium paricles" $(0.5-1 \mathrm{~mm})$ and T3"coarse particles" $(1-2 \mathrm{~mm})$ and these treatments were compared by a control treatment (without any gypsum supply). The gypsum requirement (GR) was equivalent to $30.6 \mathrm{Mg}$ ha-1 (calculated on a basis of reducing the initial ESP in soil by $90 \%$ using the equation given by USDA (1954).

The soil in each column was saturated with water through capillary rise overnight (Baruah, 1997). The infiltration experiment was conducted under ponding condition ( i.e., contenous leaching) with a constant head of $5 \mathrm{~cm}$ by a Mariotte bottle. Water used for leaching had an EC of $1.50 \mathrm{dSm}^{-1}$ and an SAR of 9.1. Six continuous increments were performed for each column $(1005 \mathrm{ml}$ per increment) after which the experiment was terminated when the overall total volume of increments was received as leachate. The saturated hydraulic conductivity, Ks is calculated using the Darcy' s equation as follow:

$$
\frac{Q}{(A . t)}=-k s\left(\frac{\Delta h}{L}\right)
$$

\footnotetext{
where, $\left(\frac{\mathbf{A h}}{\mathbf{L}}\right)$ )

is the hydraulic gradient, the quantity of water, Q, that flows out of the sample of length, L, and cross-sectional area, A, for a given hydraulic-head, $\Delta \mathrm{H}$, is measured for a given time, $\mathrm{t}$.
} 
TABLE 1. Physical and chemical properties of studied soil.

\begin{tabular}{|c|c|}
\hline Property & Value \\
\hline Particle size distribution [\%]: & \\
\hline Clay & 44.23 \\
\hline Silt & 31.27 \\
\hline Sand & 24.50 \\
\hline Texture class & Clay \\
\hline Soil moisture characteristics [\%]: & \\
\hline Saturation percent & 55.23 \\
\hline Field capacity & 27.62 \\
\hline Wilting point & 13.81 \\
\hline Density $\left[\mathrm{Mgm}^{-3}\right]$ : & \\
\hline Bulk density & 1.36 \\
\hline Total porosity [\%] & 48.68 \\
\hline Organic matter $\left[\mathrm{g} \mathrm{kg}^{-1}\right]$ & 6.20 \\
\hline $\mathrm{CaCO}_{3}\left[\mathrm{~g} \mathrm{~kg}^{-1}\right]$ & 102.3 \\
\hline EC, pH and Soluble ions: & \\
\hline $\mathrm{EC}\left(\mathrm{dSm}^{-1}\right)$ [Soil paste extract] & 21.38 \\
\hline $\mathrm{pH}$ [Soil suspension 1:2.5] & 8.44 \\
\hline Soluble ions $\left(\right.$ mmolc L $\left.^{-1}\right)$ & \\
\hline $\mathrm{Na}+$ & 175.46 \\
\hline $\mathrm{K}+$ & 4.66 \\
\hline $\mathrm{Ca}++$ & 15.22 \\
\hline $\mathrm{Mg}++$ & 20.16 \\
\hline $\mathrm{Cl}-$ & 155.20 \\
\hline $\mathrm{HCO}_{3^{-}}$ & 6.44 \\
\hline $\mathrm{SO}_{4}=$ & 53.86 \\
\hline SAR & 41.72 \\
\hline Exchangeable cations, CEC $\left(\mathrm{cmole} \mathrm{kg}^{-1}\right)$ and ESP & \\
\hline $\mathrm{Na}+\mathrm{N}$ & 12.11 \\
\hline $\mathrm{K}+$ & 1.35 \\
\hline $\mathrm{Ca}++$ & 11.93 \\
\hline $\mathrm{Mg}++$ & 15.22 \\
\hline CEC & 40.61 \\
\hline ESP & 29.82 \\
\hline
\end{tabular}

*Texture according to the USDA triangle.

\section{Simulation of one-dimension water movement}

The HYDRUS-1D code was applied to simulate water movement in variably saturated media and the equation was solved by numerical method (Šimunek et al., 2005). HYDRUS-1D code was based on the one-dimensional Richards equation, The basic water movement equation was described as:

$$
\frac{\partial \theta\left(h_{t} t\right)}{\partial t}=\frac{\partial}{\partial z}\left[k(h)\left(\frac{\partial h}{\partial z}+1\right)\right]
$$

Egypt. J. Soil Sci. 53, No. 1 (2013) 
where $\mathrm{h}$ is the soil water pressure head, $\theta$ is the volumetric water content, $\mathrm{t}$ is time, $\mathrm{z}$ is the vertical coordinate with the origin at the soil surface (negative downward) and $\mathrm{k}(\mathrm{h})$ is the unsaturated hydraulic conductivity.

For the studied experiment, the initial condition and upper boundary condition were:

$$
\begin{gathered}
\mathrm{h}(\mathrm{z}, 0)=\mathrm{h}_{\mathrm{i}}(\mathrm{z}) \\
\mathrm{h}(0, \mathrm{t})=\mathrm{h}_{0}
\end{gathered}
$$

where $h_{i}(z)$ is the initial water pressure head through the soil column and $h_{0}$ is the soil water potential at soil surface.

The free drainage was considered as the lower boundary condition:

$$
\frac{\partial h}{\partial z}=0
$$

The van Genuchten-Mualem model (van Genuchten, 1980) was applied for the studied experiment:

$$
\begin{aligned}
& \frac{\theta-\theta r}{\theta s-\theta r}=\left(1^{|\alpha h|^{n}}\right)^{-m_{h}>0} \\
& \theta=\theta_{s} \mathrm{~h} \leq 0
\end{aligned}
$$

where $\mathrm{h}$ is the soil pressure head $(\mathrm{cm}), \theta$ is the water content $\left(\mathrm{cm}^{3} \mathrm{~cm}^{-3}\right), \theta^{r}$ and $\theta \mathrm{s}$ are the residual and saturated water contents $\left(\mathrm{cm}^{3} \mathrm{~cm}^{-3}\right)$, respectively, $\alpha$, $m$ and $n$ are empirical parameters and $m=1-1 / n$.

The HYDRUS-1D code was coupled with the ROSETTA model (Schaap et al., 2001). ROSETTA model implements pedotransfer functions (PTFs) which predict the van Genuchten water retention parameters and the saturated hydraulic conductivity (Ks) in a hierarchical manner from soil textural class information, the soil textural distribution, bulk density and one or two water retention points as input. Within this experiment, the obtained results of the soil textural distribution, bulk density and the measured saturated hydraulic conductivity, $\mathrm{K}_{\mathrm{s}}$ using Darcy's equation under the impact of different gypsum radius treatments and different sequential increments of leaching were implemented in the HYDRUS-1D model to simulate the infiltration rate, cumulative infiltrationand the water movement parameters.

\section{Results and Discussion}

\section{Analysis of experimental data}

Aggregate instability increases the tendency of soils to form structural and depositional crusts (Le Bissonnais, 1996 and Wakindiki \& Ben-Hur, 2002), which are common in arid and semi-arid regions. In these regions, crusts are 
associated with several desertification factors such as reduced infiltration, enhanced run-off and intensive erosion.The physio-chemical properties of the investigated soil are characterized by a heavy texture with high salinity and sodicity (EC: $21.38 \mathrm{dSm}^{-1}$; ESP: $29.82 \%$ ) (Table 1).The variable hydraulic conductivity (HC) of soil due to sodic conditions depends on the potential of its clays to disperse (Felhendler et al., 1974, Abu-Sharar et al., 1987 and Wild, 1993). Shainberg et al.(1981) stated that soil dispersion is a function of two closely related variables: salinity and sodicity. At high salt concentration, clay dispersion decreases if the exchangeable sodium percentage (ESP) exceeds 12. Soils with exchangeable $\mathrm{Na}$ equal to or greater than $15 \%$ of their exchange capacity and low in soluble salts exhibit poor physical properties, due to $\mathrm{Na}$ exerting dispersion of clay colloids and a negative effect on macro aggregate stability (Levy and Torrento, 1995). Saline-sodic soils remain flocculated unless salts are leached from the soil. Dispersion of clay particles and their movement, and possible lodgment in the conducting pores of soils are caused by low levels of electrolytes even with low exchangeable Na (Shainberg et al., 1981, Yousaf et al., 1987 and Lebron et al., 2002).

Figure 1 shows a considerable increase in $\mathrm{HC}$ following addition of gypsum. This was short lived and the $\mathrm{HC}$ quickly decreased in subsequent leaching increments. Thus hydraulic conductivity was affected by sequential leaching and addition of gypsum fineness (Fig. 1). Gypsum increased HC by 181, 126 and $117 \%$ due to the fine-particles, medium-particles and coarse-particles gypsum, respectively (Fig.1). This trend persisted up to the $4^{\text {th }}$ leachate increment and was particularly marked where fine-particle gypsum was applied increases of up to $275 \%$ following $5^{\text {th }}$ leachate in comparison with following $1^{\text {st }}$ leachate. In soils receiving medium-particle or coarse-particle gypsum, the increase in $\mathrm{HC}$ was less marked, being up to $56 \%$ following $5^{\text {th }}$ leachate increment. $\mathrm{HC}$ of soils not supplied with gypsum decreased; the decrease was progressive with more leachate increments reaching $-51 \%$ following the $6^{\text {th }}$ leachate. Such results indicate that gypsum, particularly fine particles, caused an increase in soluble calcium ions, therefore increasing aggregation of soil particles with more $\mathrm{Ca}^{+2}$ ions on the soil exchange sites. Without gypsum amendment, persistent leaching lead to more deflocculating of clay, thus causing decreased HC.

\section{Simulation of one-dimensional water movement}

As the current results reveal that the HC is much higher under the treatment of T1 Gypsum than the other treatments, only the results of the numerical model HYDRUS-1D will be presented here to evaluate the sequential leaching increments under the impact of the fine gypsum (T1) on the water movement. Implementing the results of texture analysis, bulk density, field capacity and the measured saturated hydraulic conductivity for investigated soil in the HYDRUS1D model, the hydrological parameters $\left(\mathrm{Q}_{\mathrm{r}}, \mathrm{Q}_{\mathrm{s}}, \alpha, \mathrm{n}\right)$ can be optimized. 


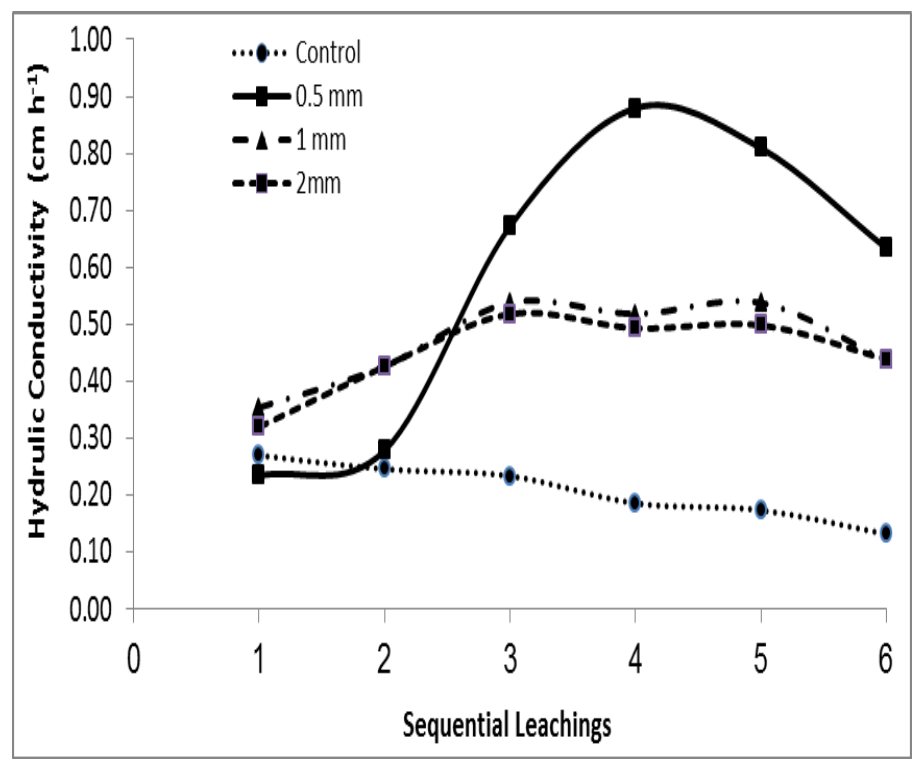

Fig.1. Hydraulic conductivity of the saline sodic $\left(21.38 \mathrm{dSm}^{-1} ; 29.82 \mathrm{SAR}\right)$ clay soil following a surface application of gypsum $\left(30.6 \mathrm{Mg} \mathrm{ha}^{-1}\right.$ equivalent) and followed by leaching with water of $1.50 \mathrm{dSm}^{-1}$ and 9.1 SAR.

The results of Fig. 2 show differences in the saturated $\mathrm{HC}\left(\mathrm{K}_{\mathrm{s}}\right)$ values between the leaching increments for soils receiving the finer particle gypsum. The differences are not large, but it supports the general supposition of the water flow as a function of time with depth. The results reveal that simulated distribution of hydraulic conductivity under the $4^{\text {th }}$ leaching increment (K4) was abundant and larger than the other increments. It required $5 \mathrm{hr}$ for the entire top soil surface $(0-30 \mathrm{~cm})$ to be fully saturated under the impact of the $4^{\text {th }}$ leaching increment (K4), while it requires $18,16,7,6$ and $7 \mathrm{hr}$ for the entire top soil surface $(0-30 \mathrm{~cm})$ to be fully saturated under the impact of the other continuous leaching increments K1, K2, K3, K5 and K6, respectively. Such change in $\mathrm{K}_{\mathrm{s}}$ may have been due to attributed to internal swelling in the soil which would be reversible and would play a major role in controlling the hydraulic properties of this soil. The changes in swelling and HC could be related to the ionic strength effect. With each subsequent leaching increment, there would be less gypsum in the soil. This suggests a possible pore-plugging by dispersed clay and slaked particles during the pre-leaching periods. Such a decrease in HC could be largely irreversible (Yousaf et al., 1987 and Curtin et al., 1994). Relationship between clay dispersion and $\mathrm{K}_{\mathrm{s}}$ can be utilized to provide an index for sodicity hazards and for predicting reduction in hydraulic conductivity. 
Fig. 2. Comparison of simulated hydraulic conductivity $\left(K_{s}\right)$ by HYDRUS-1D code with soil depth. The Six continuous increments; K1, K2, K3, K4, K5 and K6 show this simulation for soils receiving the finer particle gypsum.

For the following results, only measurements during the first $8 \mathrm{hr}$ of the experiment will be displayed in the analysis below. Using the numerical model HYDRUS-1D, the impact of the leaching increments on the infiltration rate was studied through assessing the cumulative infiltration curve in soils receiving the fine particle $(<0.5 \mathrm{~mm})$ gypsum. The cumulative infiltration curve under the Egypt. J. Soil Sci. 53, No. 1 (2013) 
different leaching increments is shown in Fig. 3. Infiltration with the $4^{\text {th }}$ leaching increment (K4) was much larger than the others. These results reflect the effect of water retention. The total cumulative infiltration after five hours of leaching increment was $1.23,1.36,2.33,2.75,2.61$ and $2.24 \mathrm{~cm}$ for $\mathrm{K} 1, \mathrm{~K} 2, \mathrm{~K} 3, \mathrm{~K} 4, \mathrm{~K} 5$ and K6, respectively. These results correspond well with the soil water storage capacity (Fig. 4) which reflects the same trend of increasing the water storage under the $4^{\text {th }}$ leaching increment (K4) compared with the other increments.

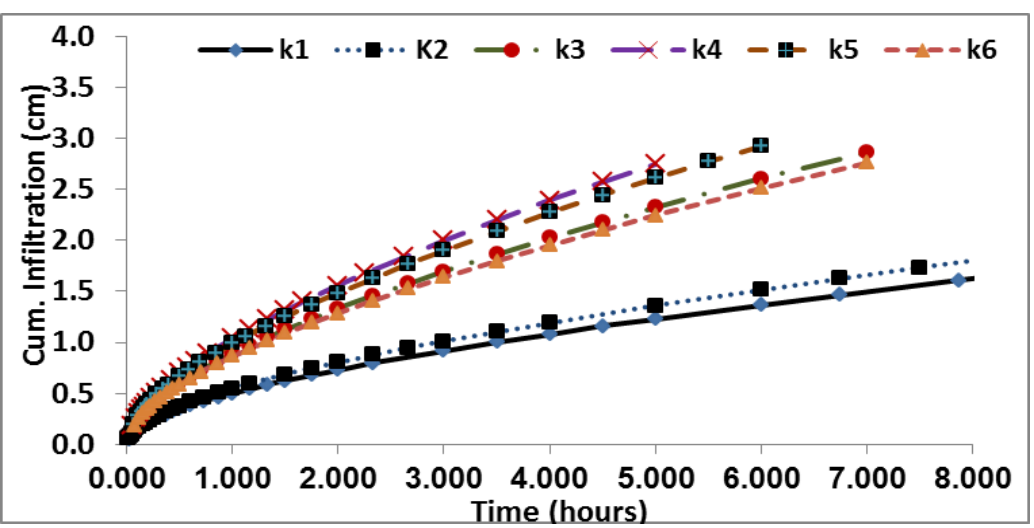

Fig. 3. Simulated cumulative infiltration by the HYDRUS-1D code versus time. The Six continuous increments; K1, K2, K3, K4, K5 and K6 show this simulation for soils receiving the finer particle gypsum.

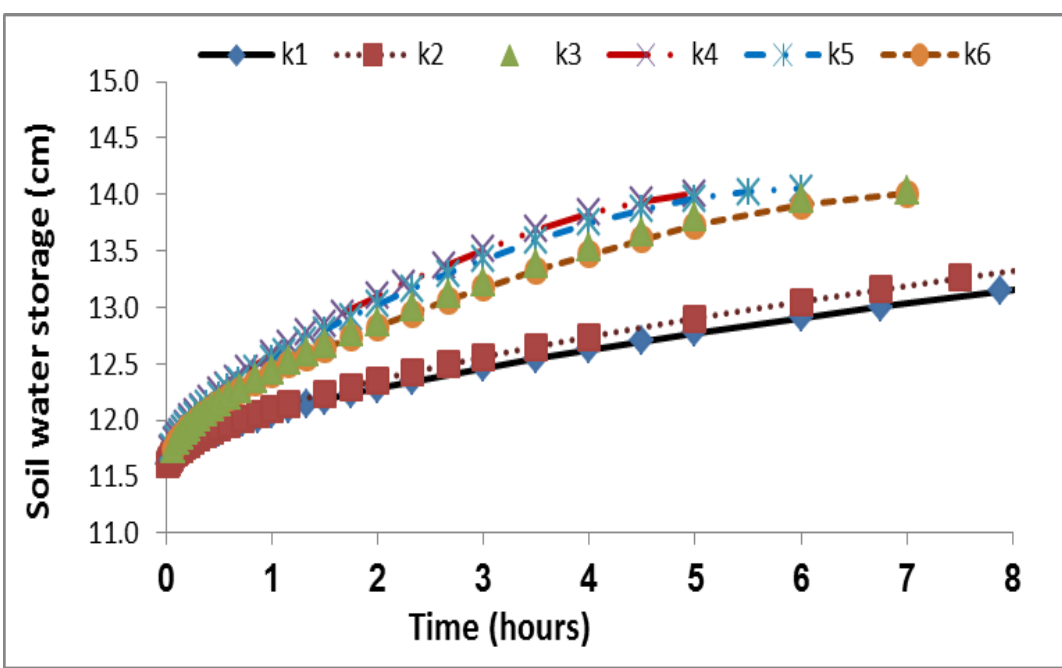

Fig. 4. Comparison of simulated water storage by HYDRUS-1D code versus time. The Six continuous increments; K1, K2, K3, K4, K5 and K6 show this simulation for soils receiving the finer particle gypsum. 
The volumetric water content was considerably higher under the $4^{\text {th }}$ leaching increment compared to the other sequential leaching increments in the top soil surface $(0-30 \mathrm{~cm})$. Fig. 5 shows water content $(\mathrm{v} / \mathrm{v})$ distribution in the top soil surface at $10 \mathrm{~cm}$ by using the numerical model of the HYDRUS-1D (Fig. 5). The volumetric water content after five hours of infiltration was constant under different sequential leaching increments (Fig. 5), with a value of 0.453, 0.456, $0.466,0.469,0.468$ and $0.466\left[\mathrm{~cm}^{3} \mathrm{~cm}^{-3}\right]$, for $\mathrm{K} 1, \mathrm{~K} 2, \mathrm{~K} 3, \mathrm{~K} 4, \mathrm{~K} 5$ and $\mathrm{K} 6$, respectively. The rate of the dissolution of gypsum in water would increase with increase in its surface area (decreasing with gypsum finnes). Kemper et al. (1975) observed that the first order dissolution coefficient of gypsum fragments in water at a given flow rate increased more rapidly as the fragment size became smaller (as the surface area increased).

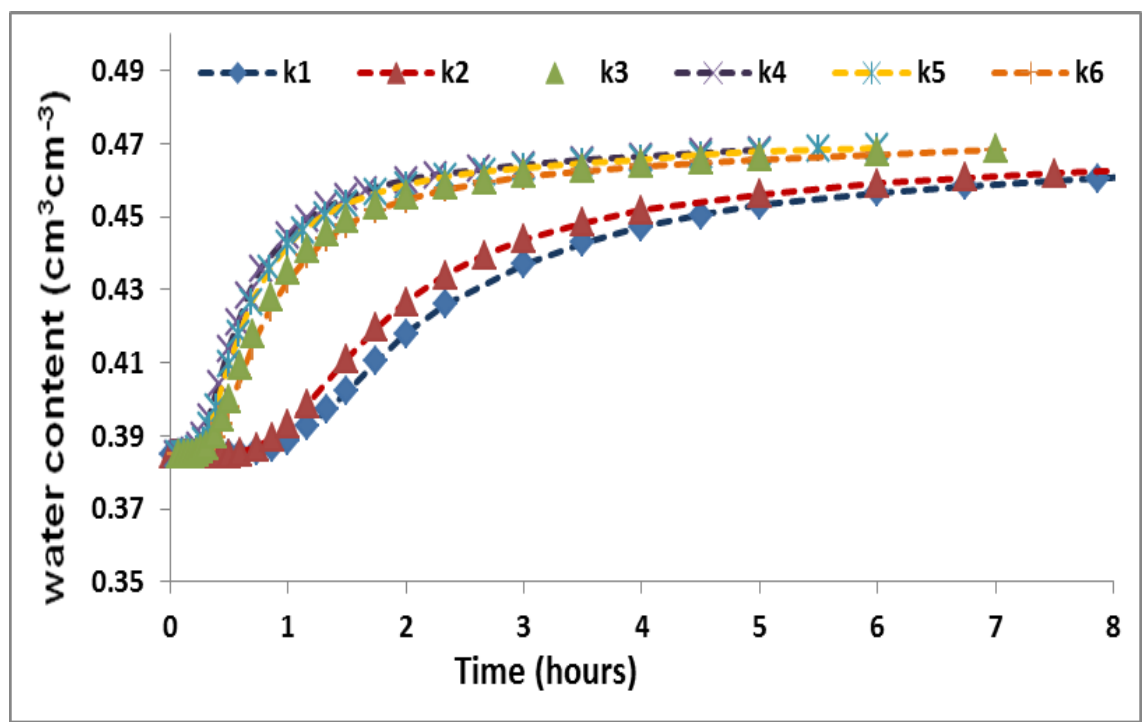

Fig. 5. Calculated water content by HYDRUS-1D code versus time at observation node $(10 \mathrm{~cm})$ depth. The Six continuous increments; K1, K2, K3, K4, K5 and K6 show this simulation for soils receiving the finer particle gypsum.

Keisling et al. (1978) displayed an exponential relationship between the first order rate coefficient and the surface area to accurately predict dissolution at various flow rates. This suggests that in addition to the differences in the surface area the sources differ in their reactivates (Barton and Wilde, 1971). In solutions containing $\mathrm{Ca}^{2+}$ and/or $\mathrm{SO}_{4}$ ions, the dissolution rate of gypsum was reported by Kemper et al. (1975) to decrease due to a $\mathrm{Ca}^{2+}$ and $\mathrm{SO}_{4}$ ion effect. When the HC was less than $1.6 \mathrm{~mm} \mathrm{~h}^{-1}$, the saturated gypsum solution would be shown in the leachate as long as solid gypsum is present in the soil. In some soils under field conditions, Bolan et al. (1991) noted that water often flows preferentially through cracks and macropores and hence a saturated concentration of gypsum

Egypt. J. Soil Sci. 53, No. 1 (2013) 
may not be maintained in such soils. The decrease in $\mathrm{K}_{\mathrm{s}}$ obtained in the current study could be attributed to clay dispersion and partially plugging of the water conducting pores (Abuhashim et al., 2009 and Lebron et al., 2002).

\section{Conclusion}

Dynamics of soil-water-movement in fields could be simulated accurately with HYDRUS-1D model. Using the model to compare, simulate and analysis the management options provide a powerful tool for agro-ecosystem assessment. Although soils of Sahl El-Tina plain are characterized as an area with continuous secondary salinization, the overall soil salinity in this region seems to have so far been kept under control by pre-season salt leaching. With addition gypsum, particularly the fine-particle material; there would be a higher solubility calcium sulfate, i.e., calcium ions, therefore increasing aggregation of soil particles. With removal gypsum from the soil, persistent leaching would be associat with increased presence of $\mathrm{Na}^{+}$ions so as to render it dominate the soil exchange complex which would lead to deflocculating, thus causing decreased HC. Therefore, for maintaining a preferable soil structure in saline-sodic soils to help obtaining efficient leaching, gypsum applied in reclamation such soils should be of fine particles.

\section{References}

Abdurrahman, H., Fatih, B., Fatih, M.K. and Mustafa, Y.C. (2004) Reclamation of saline-sodic soils with gypsum and MSW compost. Compost Sci. and Utilization 12(2):175-179.

Abuhashim, M. (2011) Impact of land use and land management on the water infiltration capacity of soils on a catchment scale. JKI, Germany.

Abuhashim, M., Lilienthal, H., Stoven, K. and Schnug, E. (2009) Characteristics of soil infiltration capacity under different agricultural management. Mitt. JKI 419: 9196.

Abu-Sharar, T.M., Bingham, F.T. and Rhoades, J.D. (1987) Reduction in hydraulic conductivity in relation to clay dispersion and disaggregation. Soil Sci. Soc. Am. J. 51: 342-346.

Arampatzis, G., Tzimopoulos, C., Sakellariou-Makrantonaki, M. and Yannopoulos, S. (2001) Estimation of unsaturated flow in layered soils with the finite control volume method. Irrigation and Drainage 50: 349-358.

Barontini, S., Ranzi, R. and Bacchi, R., (2007) Water dynamics in a gradually non homogeneous soil described by the linearized Richards equation. Water Resources Research. 
Barton, F. M. and Wilde, N. M. (1971) Dissolution rates of polycrystalline samples of gypsum and orthorhombic forms of calcium sulphate by rotating disc method. Trans Faraday SOC 67: 3590-3597.

Baruah, T.C. and Barthakur, H.P. (1997) "Soil Analysis", Vikas House, New Delhi.

Bolan, N.S., Syers, J. K. and Sumner, M. E. (1991) Dissolution of various sources of gypsum in aqueous solutions and in soil. J. Sci. Food Agric. 57: 527-541.

Bot, A.J., Nachtergaele, F.O. and Young, A. (2000) Land resource potential and constraints at regional and country levels. In: "World Soil Resources Reports", (FAO), No. 90/FAO, Rome (Italy), Land and Water Development Division.

Bridge, B.J. and Tunny, J. (1973) Effect of gypsum treatments on the swelling of natural clods of a clay soil. Soil Sci. 125: 414-419.

Brunone, B., Ferrante, M., Romano, N. and Santini, A. (2003) Numerical simulations of one-dimensional infiltration into layered soils with the Richards equation using different estimates of the interlayer conductivity. Vadose Zone Journal 2: 193-200.

Christen, E.W., Ayars, J.E. and Hornbuckle, J.W. (2001) Subsurface drainage design and management in irrigated areas of Australia. Irrig. Sci. 21:35-43.

Curtin, D., Steppuhn, H. and Selles. F. (1994) Clay dispersion in relation to sodicity, electrolyte concentration and mechanical effects. Soil Sci. Soc. Am. J. 58: 955-962.

Elmaloglou, S. and Diamantopoulos, E. (2008) The effect of intermittent water application by surface point sources on the soil moisture dynamics and on deep percolation under the root zone. Computers and Electronics in Agriculture 62: 266275.

El-Shanawany, E.A. (1985) Studies on the reclamation and management of salt affected soils at Sharkia Governorate. M.Sc. Thesis, Fac. of Agric., Zagazig Univ., Egypt.

FAO (2002) The salt of the earth: hazardous for food production. Last accessed Sept., 2008.

Felhendler, R., Shainberg, I. and Frenkel, H., (1974) Dispersion and hydraulic conductivity of soils in mixed solutions. Int. Cong. Soil Sci., Tran. 10 ${ }^{\text {th }}$ 1:103-122, (Moscow).

Keisling, T. C., Rao, P. S. C. and Jessup, R. E. (1978) Pertinent criteria for describing the dissolution of gypsum beds in flowing water. Soil Sci. Soc. Am. J. 42: 234-236.

Kemper, W. D., Olsen, J. and De Mooy, C. J. (1975) Dissolution rate of gypsum in flowing water. Soil Sci. Soc. Am. Proc.39: 458-463.

Le Bissonnais, Y. (1996) Aggregate stability and assessment of soil crustability and erodability, theory and methodology. Eu. J. Soil Sci. 47: 425-437.

Egypt. J. Soil Sci. 53, No. 1 (2013) 
Lebron, I., Suarez, D.L. and Yoshida, T. (2002) Gypsum effect on the aggregate size and geometry of three sodic soils under reclamation. Soil Sci. Soc. Am. J. 66: 92-98.

Lei, Z., Yang, S. and Xie, S. (1988) "Soil Water Dynamics", Tsinghua University Press, Beijing.

Levy, G.J. and Torrento, J.R. (1995) Clay dispersion and macroaggregate stability as affected by exchangeable potassium and sodium. Soil Sci. 160: 352-358.

Milla, K. and Kish, S. (2006) A low-cost microprocessor and infrared sensor system for automating water infiltration measurements. Computers and Electronics in Agriculture 53: 122-129.

Mishra, S.K., Kumar, S.R. and Singh, V.P. (1999) Calibration and validation of a general infiltration model. Hydrological Processes 13: 1691-1718.

Mishra, S.K., Tyagi, J.V. and Singh, V.P. (2003) Comparison of infiltration models. Hydrological Processes 17: 2629-2652.

Miyamoto, S. and Enriquez, C.A. (1990) Comparative effects of chemical amendments on salt and sodium leaching. Irrigation Sci. 11(2):83-92.

Murtaza, G., Ghafoor, A. and Qadir, M. (2006) Irrigation and soil management strategies for using saline-sodic water in a cotton-wheat rotation. Agric. Water Manage, 81: 98-114.

Page, A.L. (1986) "Methods of Soil Analysis, Part 2: Chemical and Microbiological Properties", ASA-SSA, Madison, Wisconsin, USA.

Ramirez, H., Rodriguez, O. and Shainberg, I. (1999) Effect of gypsum on furrow erosion and intake rate. Soil Sci. 164 (5):351-357.

Schaap, M.G., Leij, F.J. and van Genuchten, M.Th. (2001) ROSETTA: a computer program for estimating soil hydraulic parameters with hierarchical pedotransfer functions. Journal of Hydrology 251:163-176.

Shainberg, I., Rhoades, J.D., Suarez, D.L. and Parther, R.J. (1981) Effect of mineral weathering on clay dispersion and hydraulic conductivity of sodic soils. Soil Sci. Soc. Am. J. 45: 287-291.

Šimunek, J., van Genuchten, M.Th. and Šejna, M. (2005) The HYDRUS-1D software package for simulating the one-dimensional movement of water, heat, and multiple solutes in variably-saturated media. Version 3.0, HYDRUS Software Series 1, Department of Environmental Sciences, University of California Riverside, Riverside, CA, p. 270.

Singh, R. (2004) Simulations on direct and cyclic use of saline waters for sustaining cotton-wheat in a semi-arid area of north-west India. Agric. Water Manage. 66: 153162. 
Siyal, A.A., Siyal, A.G. and Abro, Z.A. (2002) Salt affected soils their identification and reclamation. Pak. J. of App. Sci. 2 (5):537-540.

USDA (1954) "Diagnosis and Improvement of Saline and Alkali Soils", Agriculture HandBook No. 60, US Gov. Printing Office, Washington, USA.

Van Genuchten, M.Th. (1980) A closed-form equation for predicting the hydraulic conductivity of unsaturated soils. Soil Sci.Soc. Am. J. 44: 892-898.

Wakindiki, I.C. and Ben-Hur, M. (2002) Soil mineralogy and texture effect on crust micromorphology. Infiltration, and erosion. Soil Sci. Soc. Am. J. 66: 897-905.

Wild, A. (1993) "Soils and the Environment", Cambridge University Press, Cambridge.

Willis, T.M., Black, A.S. and Meyer, W.S. (1997) Estimates of deep percolation beneath cotton in the Macquarie Valley. Irrig. Sci. 17:141-150.

Yousaf, M., Ali, O.M. and Rhoades, J.D. (1987) Clay dispersion and hydraulic conductivity of some salt-affected arid land. Soil Sci. Soc. Am. J. 51:905-917.

(Received 16/4/2013; accepted $28 / 12 / 2013$ ) 


$$
\begin{aligned}
& \text { تأثير حجم حبيبات الجبس على خواص التربـة الفيزيائيسة لأراضى } \\
& \text { ملحية صودية من شمال سيناء، مصر حر حرائر } \\
& \text { محمد أبوهاثم و محمد كمال عبد الفتاح }
\end{aligned}
$$

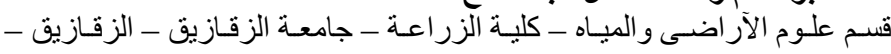

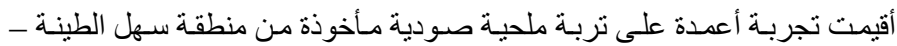

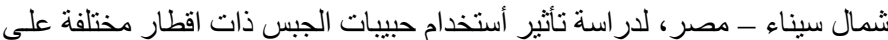

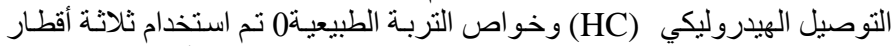

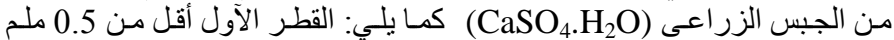

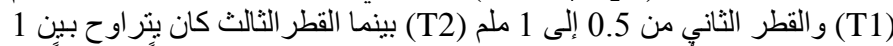

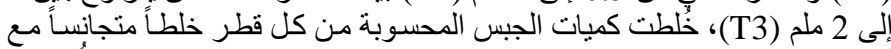

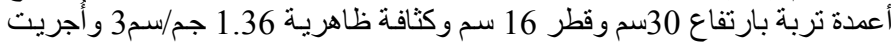

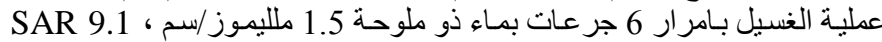

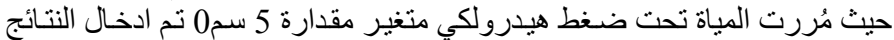
المتحصل عليها إلى الموديل الرقىى

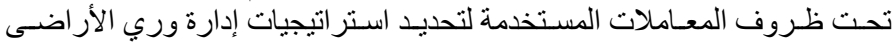

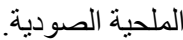

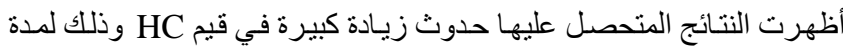

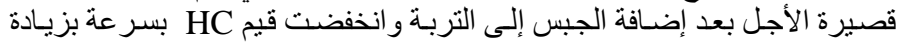

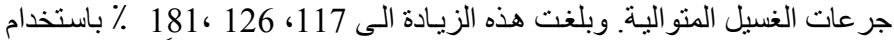

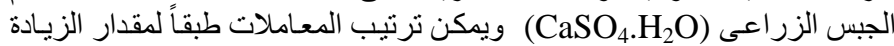

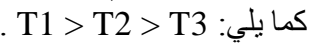

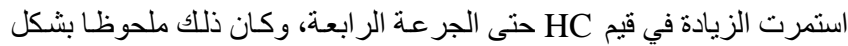

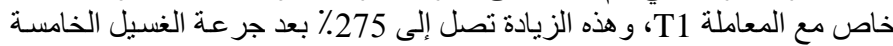

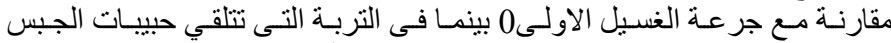

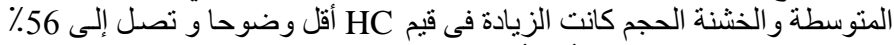

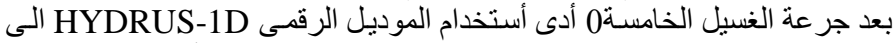

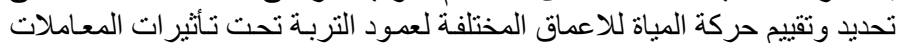

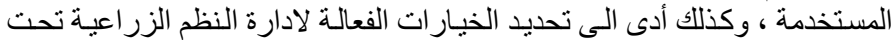

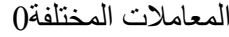

